\title{
Tecnologia Ambiental aplicada ao Gerenciamento e Processamento de resíduos industriais no Estado do Paraná
}

\author{
Marisa Soares Borges*
} Ronald Jesus da Conceição

O presente artigo tem a finalidade de apresentar e discutir alguns aspectos gerais da tecnologia ambiental no âmbito do processo de gerenciamento e aproveitamento de resíduos sólidos industriais como matéria-prima para o desenvolvimento de novos materiais. Com o objetivo de sustentar um enfoque econômico na análise destaca-se a importância da tecnologia ambiental para o fortalecimento da competitividade e eficiência das empresas do setor industrial no Estado do Paraná; em seguida, apresenta-se sucintamente os principais mecanismos legais e normativos estabelecidos pela Resolução n. ${ }^{\circ}$ 313/2002 do Conselho Nacional do Meio Ambiente (CONAMA) que dispõe sobre o inventário de resíduos sólidos industriais. Por fim, argumenta-se que a adoção de propostas e investimentos em programas para o gerenciamento e aproveitamento de resíduos industriais deve fazer parte do sistema agregado de inovação tecnológica nas indústrias paranaenses.

Num primeiro momento, para evidenciar a importância da tecnologia ambiental no processo de aproveitamento de resíduos industriais, ressalta-se que, para um crescimento econômico sustentável a longo prazo, deve existir uma busca pelo chamado ecodesenvolvimento industrial (Sachs; 1986); em linhas gerias, esta nova trajetória de desenvolvimento requer políticas estratégicas que incluem o meio ambiente como um dos fatores que podem aumentar a sustentabilidade da estrutura produtiva da indústria

Fundamentalmente, os resíduos sólidos industriais podem ser definidos como aqueles oriundos do processo produtivo cujas particularidades tornem indesejável o seu lançamento no meio ambiente, ou que exijam para isto soluções técnicas e/ou econômicas em face da melhor tecnologia disponível (CONAMA; 2002).

O conceito de aproveitamento de resíduos industriais se agrega a interdisciplinariedade da questão ambiental, focalizando a necessidade de buscar o desenvolvimento a partir de soluções gerenciais e tecnológicas que atendam à legislação

\footnotetext{
* Mestre em Engenharia Química. Gerente Administrativa do Laboratório de Tecnologia Ambiental da Universidade Federal do Paraná (UFPR). Endereço eletrônico: marisa@ufpr.br

** Graduando em Ciências Econômicas pela Universidade Federal do Paraná (UFPR). Bolsista do Centro de Pesquisas Econômicas (CEPEC/UFPR). Endereço eletrônico: ronald.jesus@ufpr.br
} 
ambiental vigente e que, ao mesmo tempo, sejam compatíveis com o processo de crescimento econômico sustentável.

No argumento de Romeiro \& Filho (1997), “o uso de um determinado bem ambiental por uma empresa passa a representar um custo; por conseguinte, a locação eficiente destes recursos é determinada através de um processo de barganha entre o custo em poupá-lo (controle de resíduos) e seu preço na margem (custo de degradação)". Neste contexto, é necessário que sejam implementadas, por parte das empresas, ações para quantificar e caracterizar os resíduos industriais, de modo a definir os sistemas de tratamento ou condicionamento mais adequados.

As indústrias podem implementar tecnologias apropriadas com a finalidade de reutilizar a geração de sobras industriais para: i) minimizar os custos operacionais a partir do cumprimento das leis e normas ambientais do país; ii) minimizar os custos de produção a partir da utilização de tecnologias limpas (clean technologies) na forma de redução de energia e insumosmatérias-primas; iii) aplicar processos de inovação tecnológica para controlar e reduzir os impactos ambientais; iv) adotar mecanismos de integração entre empresas, órgãos governamentais e centros de pesquisa a fim de incentivar o desenvolvimento na área de tecnologia ambiental (Lerípio; 2001).

Os resíduos são originados das atividades dos diversos setores da indústria, podendo ser representados por cinzas, lodos, plásticos, papéis, madeiras, fibras, borrachas, metais, escórias, vidros e cerâmicas, etc. Tais resíduos são classificados com base na sua periculosidade e solubilidade. De acordo com a Norma Brasileira (NBR) n. ${ }^{\circ} 10.004$ a 10.007, os resíduos industriais podem ser classificados como sendo: i) resíduos de classe I que são perigosos, tendo periculosidade por inflamabilidade, corrosividade, reatividade, toxicidade ou patogenicidade; ii) resíduos de classe II que são não-inertes, podendo ter propriedades como combustibilidade, biodegradabilidade ou solubilidade em água; e iii) os resíduos de classe III que são inertes, não representando maiores problemas para a saúde pública ou riscos para o meio ambiente.

Considerando que a grande diversidade das atividades antrópicas ocasiona, durante o processo produtivo industrial, a geração de resíduos que poluem e contaminam o meio ambiente, algumas indústrias paranaenses estão realizando programas internos para o aproveitamento dos seus resíduos sólidos.

Com efeito, está se tornando consenso entre os técnicos ambientais das indústrias paranaenses que o aproveitamento de 'sobras' ainda na fonte geradora, diminui o volume total 
de resíduos, reduz os gastos operacionais e, em grande parte dos casos, pode gerar uma nova receita para a indústria.

A recente demanda pela busca de soluções por parte das empresas e órgãos governamentais, para resolver os problemas da geração de resíduos industriais, tem aumentado de forma considerável. Entretanto, a forma limitada como as informações sobre os resíduos industriais estão disponibilizadas podem não permitir um amplo desenvolvimento de processos e produtos por parte das empresas e institutos de pesquisa.

Para suprir essa crescente necessidade de quantificar e caracterizar os resíduos industriais, de modo a definir os sistemas de gerenciamento e processamento mais adequados, foi estruturado um instrumento de política de gestão de resíduos industriais no Brasil, a partir da resolução do CONAMA n. 313, de 29 de outubro de 2002, que estabelece a obrigatoriedade da realização do inventário de resíduos industriais.

O inventário nacional de resíduos industriais é o conjunto de informações sobre a geração, características, armazenamento, transporte, tratamento, reutilização, reciclagem, recuperação e disposição final dos resíduos sólidos gerados pelas indústrias do país. De acordo com a resolução n. 313, os resíduos existentes ou gerados pelas atividades industriais serão objetos de controle específico, como parte integrante do processo de licenciamento ambiental.

Segundo dados da pesquisa sobre a competitividade da indústria brasileira, realizada pelo Conselho Nacional da Indústria (CNI) e pelo Banco Nacional de Desenvolvimento Econômico e Social (BNDES), a principal motivação das empresas para realizarem investimentos ambientais foi o atendimento a legislação; entre os anos de 1999 e 2000, 72,2\% das empresas industriais concretizaram investimentos para cumprir as normas ambientais da legislação brasileira e estadual. Cerca de 30\% das indústrias, realizaram investimentos em gestão, controle e melhorias operacionais e tecnológicas e otimizaram a utilização de insumos a partir da redução de resíduos sólidos (Visão Estratégica; 2003).

Seguindo a classificação do Instituto Brasileiro de Geografia e Estatística (IBGE), apresenta-se a seguir, os ramos industriais que são obrigados a prestar informações para o órgão estadual de meio ambiente, sobre os resíduos gerados no processo produtivo: i) preparação de couros e fabricação de artefatos de couro, artigos de viagem e calçados; ii) fabricação de coque, refino de petróleo, elaboração de combustíveis nucleares e álcool; iii) fabricação de produtos químicos; iv) metalurgia básica; v) fabricação de produtos de metal, exclusive máquinas e equipamentos; vi) fabricação de máquinas e equipamentos; vii) 
fabricação de máquinas para escritório e equipamentos de informática; viii) fabricação e montagem de veículos automotores; ix) fabricação de outros equipamentos de transporte.

No Estado do Paraná, a Lei Estadual n. 12.493/1999, estabeleceu a obrigatoriedade da fonte geradora de resíduos sólidos industriais se cadastrar no Instituto Ambiental do Paraná (IAP), informando quantidades e tipos de resíduos gerados para fins de controle e inventário.

Dessa forma, a partir do inventário de resíduos industriais é possível diagnosticar a situação atual da geração e destinação final de resíduos sólidos do parque industrial do Estado, inventariando suas quantidades, tipologia, formas de armazenamento e disposição final adotadas pelas indústrias paranaenses, bem como os estoques existentes em suas instalações.

O Estado do Paraná possui um diversificado parque industrial. Segundo dados da Federação das Indústrias do Estado do Paraná (FIEPR; 2006) o complexo industrial paranaense possui 5.923 indústrias com aproximadamente 30 mil estabelecimentos industriais, evidenciando a diversidade produtiva nos mais diferentes setores. Por outro lado, estima-se que são geradas mais de 30 mil toneladas/mês de resíduos (classe I, II e III) de classe perigosa e não-inerte (IAP; 2005). Cerca de 20\% deste volume é disposto em aterros sanitários ou são enviados para processamento. Outra parte dos resíduos é estocada para uma destinação final.

Considerando a ausência de informações sobre os tipos e destinos dos resíduos gerados no parque industrial do Paraná, torna-se necessário uma criteriosa avaliação ambiental, evidenciando que, além das viabilidades técnicas e mecânicas, o aproveitamento desses resíduos representa ganho de equilíbrio sob o ponto de vista do crescimento econômico.

Em decorrência do potencial de valorização dos resíduos industriais no Estado do Paraná, será possível a concretização dos principais objetivos: i) implementar uma política estadual de gestão de resíduos sólidos industriais; ii) difundir tecnologias mais limpas que possibilitem a redução significativa de resíduos; iii) aumentar o processo de reutilização, reciclagem e eliminação da destinação final inadequada dos resíduos; iv) viabilizar novos empreendimentos de gerenciamento e reutilização de resíduos; v) gerar indiretamente novas fontes de empregos e renda; e vi) disponibilizar uma base de dados para novas pesquisas e desenvolvimento tecnológico.

A estratégia para a elaboração do inventário de resíduos industriais consiste em aproximar os órgãos do governo, o setor produtivo e os centros de pesquisa, para que as políticas ambientais incentivem as atividades de pesquisa e desenvolvimento (P\&D). Neste 
sentido, a título de ilustração, menciona-se uma parceria de pesquisa e desenvolvimento entre o Laboratório de Tecnologia Ambiental da Universidade Federal do Paraná (UFPR) e uma empresa montadora de veículos da Região Metropolitana de Curitiba; esta parceria teve o objetivo de elaborar o inventário de resíduos industriais e viabilizar um processo específico de reaproveitamento de borra de fosfato gerado a partir da pintura em superfícies metálicas.

No que se refere ao uso de tecnologias ambientais por parte das indústrias, fica evidente que deve existir um firme relacionamento entre as organizações governamentais, industrias e centros de pesquisas.

Vale ressaltar que a consolidação das leis ambientais e a participação da sociedade aumentaram a atuação e o rigor dos órgãos ambientais federal, estadual e municipal, obrigando que as indústrias modifiquem as interações com o meio ambiente ou, de forma negativa, ampliem seu quadro jurídico para enfrentar possíveis demandas no campo do direito ambiental. Para evitar este tipo de situação, um significativo número de indústrias de médio e grande porte já implanta, ou está implantando, processos de tecnologia ambiental para adequar suas atividades às exigências das normas ambientais.

Por fim, destaca-se que o uso de tecnologias ambientais para o gerenciamento e processamento de resíduos industriais que aliem a eficiência com a redução de custos são de fundamental importância para o desenvolvimento ambiental e econômico.

\section{Referências Bibliográficas}

CONSELHO NACIONAL DO MEIO AMBIENTE (CONAMA). Resolução 313/2002. Disponível na Internet: http://www.mma.gov.br/port/conama/res/res02/res31302.html. Acesso: jun. de 2006.

FEDERAÇÃO DAS INDÚSTRIAS DO PARANÁ (FIEPR). Sondagem industrial (vários). Disponível na Internet: http://www.fiepr.org.br/fiepr/analise. Acesso: jun. de 2006.

FELLENBERG, G. (1980). Introdução aos problemas da poluição ambiental. São Paulo: EPU.

INSTITUTO AMBIENTAL DO PARANÁ (IAP). Resíduos sólidos. Disponível na Internet: http://www.pr.gov.br/meioambiente/iap/index.shtml. Acesso: jun. de 2006.

LERÍPIO, A. A. (2001). Um método de gerenciamento de aspectos e impactos ambientais. (Tese de Doutorado). Universidade Federal de Santa Catarina (UFSC).

ROMEIO, A. R. \& FILHO, S. S. (1997). 'Dinâmica de inovações sob restrição ambiental'. In: Economia do meio ambiente. Campinas: IE/UNICAMP, p. 83-122.

SACHS, I. (1986). Ecodesenvolvimento: crescer sem destruir. São Paulo: Vértice.

VISÃO ESTRATÉGICA (2003). Relatório de Sustentabilidade Empresarial. Vol. I. Conselho Empresarial Brasileiro para o Desenvolvimento Sustentável. 
